\title{
Application of Geopolymer Cement for Groutless Decorative Building Materials
}

\author{
Sotya Astutiningsih \\ Department of Metallurgy and Materials Engineering, University of Indonesia, Depok 16424, Indonesia
}

\begin{abstract}
The present study describes the experiments on the application of geopolymer paste for groutless in situ casting or flooring. The paste was synthesized from fly ash and sodium silicate solution and cured at room temperature, 60 and $80^{\circ} \mathrm{C}$ for 24 hours. To simulate flooring application, the geopolymer paste was casted on Portland cement cubes which have been fully hydrated for 28 days. Silica fume was added to reduce cracks but at the same time compressive strength decreased. Averaged compressive strength decreased from $53 \mathrm{MPa}$ to $37 \mathrm{MPa}$ for paste cured at $60^{\circ} \mathrm{C}$. Curing at higher temperatures produced stronger geopolymer, with compressive strength of $12 \mathrm{MPa}, 53 \mathrm{MPa}$ and $67 \mathrm{MPa}$ for geopolymer cured at room temperature, $60^{\circ} \mathrm{C}$ and $80^{\circ} \mathrm{C}$ respectively, however, higher curing temperature resulted in more cracking when the geopolymer paste was applied on the Portland cement substrate. Averaged hardness values were 65 and 43 Brinnel scale (BHN), and wear rate, measured using Ogoshi machine, were 0.66 and $1.80 \mathrm{~mm}^{3} / \mathrm{min} \mathrm{for}^{\circ}$ samples cured at 60 and $80^{\circ} \mathrm{C}$ respectively. Unless surface hardening was applied, the material is not suitable for flooring but do so for decorative masonry.
\end{abstract}

Key words: Geopolymer, groutless flooring, near-net shaping, hardness, wear.

\section{Introduction}

Ceramic tiles are probably the most popular floor covering since they cover a wide range of colour, patterns, size, shapes and prices. Raw materials for the fabrication of ceramic tiles are basically clay mineral, which belong to the aluminosilicate minerals having layered structures. Under a scanning electron microscope, clay particles are of flaky shapes. These flakes are alternating layers of tetrahedral silica and octahedral alumina. This layered structure of clay makes it plastic when wet. This mixture of clay and water was formed and then fired at high temperatures of above $700^{\circ} \mathrm{C}$. The high temperature firing makes ceramic tiles cannot be custom applied or casted insitu. Groutless flooring and covering can be realized using ordinary Portland cement, terrazzo or vinyl covering on concrete. Ordinary Portland cement covering is the cheapest alternative but may not be suitable for decorative purpose. Vinyl covering comes into

Corresponding author: Sotya Astutiningsih, $\mathrm{PhD}$, research fields: geopolymer and cement-based materials. E-mail: sotya.astutiningsih@ui.ac.id. different colours and patterns but heat resistance is low. Terazzo floor is probably the best choice but higher in price. It is prepared from basically white Portland cement mixed with ornamental crushed stones like granites which was casted and polished. Insitu casting produces groutless floor or covering which is required for high standard of hygiene like hospitals and laboratories. Geopolymer is a good option for groutless flooring since it can be casted insitu without the need for high temperature firing nor polishing, just like concrete but with better surface quality. Smooth and textured surfaces can be easily produced by applying “surface mold”. Dark and bright colour geopolymer can be made using fly ash and kaolin or by adding pigment to kaolin. Furthermore, geopolymer material has better resistance to acid and heat [1] compared to terrazzo, which is basically ordinary Portland cement — based material.

Geopolymer is an alternative substitute for Portland Cement having better properties in chemical resistance [2], earlier strength development [3] and near net shaping surface. Geopolymer product was first patented by a French scientist, Professor Davidovitts 
who founded Geopolymer Institute in 1979. Geopolymer can be synthesized from minerals or industrial waste containing high amount of silica and alumina in their reactive glassy state which can be activated with alkaline silicate solutions. Clay minerals, which contain low impurities, have been extensively studied as geopolymer precursor [2, 4-6]. For building construction materials, fly ash, the unburnt residue from coal burning in a power plant, has been utilized as Portland cement substitute for concrete. Fly ash is a cheaper alternative to clay, however it contains significant amount of oxides unwanted for the geopolymer synthesis like calcium and iron oxides. It is these impurities, especially carbon and iron oxides that make fly ash dark in colour. On the other side, the low content of impurities in kaolin is the reason for the light, almost white, colour/shade. The role of calcium oxide in the reaction synthesis and geopolymer properties have been studied [7-10], while that for iron oxide has not been studied thouroughly. However, the role of impurities is not a concern in the present study.

The compressive and flexural strength of geopolymer concrete is comparably higher to Portland cement concrete, but geopolymer possesses significantly higher early strength due to the different curing mechanism. Curing of the geopolymer paste can be done at below $120^{\circ} \mathrm{C}$ to room temperature [11]. Curing is a polycondensation reaction in which crosslinking of oligomers produced from the previous reaction stage of dissolution of the alumina -silica precursor in high alkalinity environment. From this reaction water molecules were produced as by product. On the other hand, for the hardened cement paste water molecules in the hydrated products would evaporate at above $300^{\circ} \mathrm{C}$ causing shrinkage followed by decomposition of the hydrates into free lime $(\mathrm{CaO})$ at between $450-500^{\circ} \mathrm{C}$. Carbonation of $\mathrm{CaO}$ then occurs at $500^{\circ} \mathrm{C}$. The carbonates will then decompose at $800^{\circ} \mathrm{C}$. On the contrary, neither phase transformation nor chemical reactions occur during heating of geopolymer up to $1,000^{\circ} \mathrm{C}$.
In this experiment, geopolymer has been synthesized from fly ash and sodium silicate solution. The concentration of the sodium silicate solution and the ratio between fly ash and the solution was adjusted to obtain the desired viscosity or workability of the paste and strength of the cured geopolymer. Characterisation of the cured geopolymer includes compressive strength, appearance of the geopolymer surface, hardness and wear rate.

\section{Experiments}

Geopolymer made for this study was synthesized from fly ash and sodium silicate solution forming a cementitious paste which was then casted onto a substrate of Portland cement concrete cubes of $30 \times 30$ $\times 30 \mathrm{~cm}^{3}$. To secure a fully hydrated concrete, the cubes had been immersed in water for 28 days. The thickness of the paste will be made $8 \mathrm{~mm}$. Some textured surface like wood and plastic tapes were pressed on to the paste surface to get surface variation. After application of the geopolymer, the samples were cured for 24 hours at room temperature and $80^{\circ} \mathrm{C}$. Curing was done in sealed molds. Characterization of the products includes compressive strength, hardness and wear rate of the geopolymer paste. ASTM C39 was referred for the compressive strength measurement using crushing test machine with the specimens' dimension of $5 \times 5 \times 5 \mathrm{~cm}^{3}$ cubes. Each of the compressive strength value is the average of three tests. Ogoshi machine was used to measure the wear rate, while hardness measurement was performed according to ASTM E-10 for BHN (Brinnel Hardness Number). The dimension of samples for wear rate and hardness testing was $3 \times 4 \times 1 \mathrm{~cm}^{3}$ and each value of wear rate and hardness was the average of three measurements.

The Brinnel hardness test uses a steel ball of 3.2 $\mathrm{mm}$ diameter indented to the specimen at a load of $62.5 \mathrm{~kg}$. The load is applied for $30 \mathrm{~s}$ and the indentation left at the specimen is measured using a low magnification optical microscope. Two reading of 
diameter should be measured at right angle and averaged. The BHN (Brinnel Hardness Number) is expressed in Eq. (1) [12].

$$
2-2-2
$$

where, $\mathrm{P}=$ applied load, kg,

$\mathrm{D}=$ diameter of ball, $\mathrm{mm}$,

$\mathrm{d}=$ diameter of indentation.

Fig. 1 describes the wear measurement principle using Ogoshi machine. A rotating disc is exposed on to a rectangular specimen at a specified length or specified period. The thickness of the indentation caused by the rotating disc is measured using a low magnification optical microscope. Wear rate is expressed by the volume loss of material in a unit length or time. Eq. (2) denotes wear rate in volume loss per time, $\mathrm{mm}^{3} / \mathrm{min}$, while the volume loss is expressed in Eq. (3). This experiment used a rotating disc of $3 \mathrm{~mm}$ thick with a radius of $15 \mathrm{~mm}$ and a distance length of $200 \mathrm{~m}$ with rotating speed of 1.97 $\mathrm{m} / \mathrm{s}$.

where, $\mathrm{Vi}=$ initial volume of the material, $\mathrm{mm}^{3}$,

$\mathrm{V}_{\mathrm{f}}=$ volume after test, $\mathrm{mm}^{3}$,

$\mathrm{t}=$ time of test, $\min$.

$$
2 \quad-12-22-24
$$

where, $\mathrm{B}=$ the thickness of the rotating disc, $\mathrm{mm}$.

$\mathrm{r}=$ disc radius, $\mathrm{mm}$.

$\mathrm{b}=$ the thickness of the indentation, $\mathrm{mm}$.

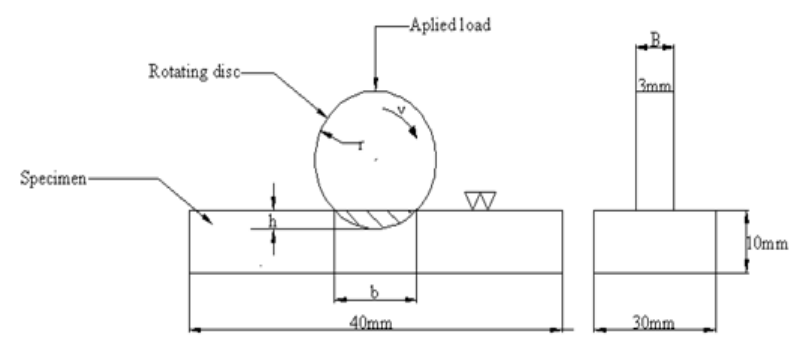

Fig. 1 Schematic representation on wear testing using Ogoshi machine.

Fly ash used was supplied from Suralaya power plant in the island of Java, Indonesia. Table 1 shows the chemical composition of the fly ash using Energy Dispersive Spectrometry. The fly ash was mixed with sodium silicate solution of certain composition resulting in a paste with sufficient workability which was then applied onto the concrete cubes and then cured at the mentioned temperatures and time. The overall composition of the geopolymer paste was presented in Table 2. Composition denomination referred to Rahier and colleagues [4]. Pure sodium silicate solution has been used throughout the experiments.

\section{Results and Discussion}

Fig. 2 shows the cured geopolymers casted on the concrete surface. A closer observation revealed cracks

occurring on the geopolymer layer. These cracks developed soon after the hardened paste was removed from the sealed mold. Geopolymer paste with a dimension of $30 \mathrm{~cm} \times 30 \mathrm{~cm}$ with thickness of $8 \mathrm{~mm}$ (not applied to concrete cube substrate) has been made Table 1 Chemical composition of fly ash.

\begin{tabular}{ll}
\hline Elements & Weight \% \\
\hline $\mathrm{Al}_{2} \mathrm{O}_{3}$ & 30.27 \\
$\mathrm{SiO}_{2}$ & 51.14 \\
$\mathrm{~K}_{2} \mathrm{O}$ & 1.46 \\
$\mathrm{CaO}$ & 5.43 \\
$\mathrm{TiO}_{2}$ & 2.85 \\
$\mathrm{MnO}$ & 0.18 \\
$\mathrm{FeO}$ & 7.75 \\
$\mathrm{MgO}$ & 3.27 \\
$\mathrm{NiO}$ & 0.1 \\
$\mathrm{Na}_{2} \mathrm{O}$ & 2.32 \\
$\mathrm{P}_{2} \mathrm{O}_{5}$ & 0.38 \\
\hline
\end{tabular}

Table 2 Composition of geopolymer paste in molar ratios.

\begin{tabular}{lc}
\hline Elements/compounds & Molar ratios \\
\hline $\mathrm{Na} / \mathrm{Al}$ & 0.3277 \\
$\mathrm{Si} / \mathrm{Al}$ & 1.5965 \\
$\mathrm{H}_{2} \mathrm{O} / \mathrm{Na}_{2} \mathrm{O}$ & 15.9596 \\
$\mathrm{SiO}_{2} / \mathrm{Na}_{2} \mathrm{O}$ & 0.9818
\end{tabular}




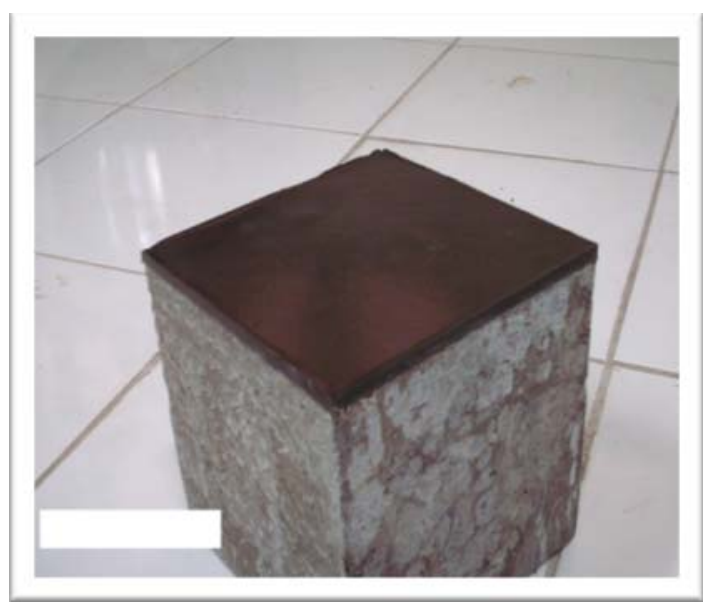

Fig. 2 Fly ash based-geopolymer layer on a Portland cement concrete cube substrate.

and showed that there was no visible cracks formed, however the $8 \mathrm{~mm}$ thick layer curved which indicates shrinkage. For that reason, silica fume was added to the paste as filler to accommodate shrinkage. Undensified silica fume was used instead of sand to retain the smooth surface of the resulting paste. The addition of 5\% weight (wt) silica fume decreased the compressive strength of the geopolymer paste. Segregation of this undensified silica fume was suspected for the decrease in strength. The addition of silica fume to reduce cracks has not been successful but instead decreased strength. Silica flour, made by grinding silica sand, should be added instead. The compressive strength of the geopolymer paste after 24 hour curing at ambient temperature $\left(28^{\circ} \mathrm{C}\right), 60^{\circ} \mathrm{C}$ and $80^{\circ} \mathrm{C}$ was shown in Table 3.

In general, higher curing temperature with the same curing time resulted in higher compressive strength; however observation on the geopolymer layers on the concrete substrate revealed that the higher curing temperature resulted in more severe cracking. It can be assumed that high curing/heating rate would result in more severe cracking. There is a compromise between strength and cracking with curing temperature/rate. To achieve an optimum strength with minimum cracking, geopolymer layered on the concrete substrate should be cured at low temperature, for example at room temperature, for longer time.
Hardness and wear resistance are properties required for materials used for flooring or benchtop. Wear rate using Ogoshi machine and Brinnel Hardness of fly ash-based geopolymer cured at room temperature and at $80^{\circ} \mathrm{C}$ were shown in Table 4 . These measurements were performed at 30 days after curing of the geopolymer. Hardness of these fly ash-based geopolymers is in the same range as metakaolin-based geopolymer synthesized in previous experiments [13] which is close to the hardness of mineral gypsum or approximately 2 in the Mohs' scale. Hardness and wear resistance of geopolymer cured at $80^{\circ} \mathrm{C}$ were lower than the one cured at room temperature which is very

Table 3 Compressive strength of geopolymer paste after 24 hours curing at different temperatures.

\begin{tabular}{|c|c|c|}
\hline Specimens/curing & $\begin{array}{l}\text { Compressive strength } \\
(\mathrm{MPa})\end{array}$ & $\begin{array}{l}\text { Averaged } \\
\text { compressive } \\
\text { strength (MPa) } \\
\end{array}$ \\
\hline \multicolumn{3}{|c|}{ Geopolymer paste cured at ambient temperature $28^{\circ} \mathrm{C}$} \\
\hline 1 & 12.152 & \multirow{3}{*}{12.021} \\
\hline 2 & 12.152 & \\
\hline 3 & 11.76 & \\
\hline \multicolumn{3}{|c|}{ Geopolymer paste cured at $60^{\circ} \mathrm{C}$} \\
\hline 1 & 48.980 & \multirow{3}{*}{52.721} \\
\hline 2 & 57.143 & \\
\hline 3 & 52.041 & \\
\hline \multicolumn{3}{|c|}{$\begin{array}{l}\text { Geopolymer paste with } 5 \% \text { wt addition of silica fume cured a } \\
60^{\circ} \mathrm{C}\end{array}$} \\
\hline 1 & 42.857 & \multirow{3}{*}{36.735} \\
\hline 2 & 34.694 & \\
\hline 3 & 32.653 & \\
\hline \multicolumn{3}{|c|}{ Geopolymer paste cured at $80^{\circ} \mathrm{C}$} \\
\hline 1 & 68.992 & \multirow{2}{*}{66.581} \\
\hline 2 & 64.1704 & \\
\hline
\end{tabular}

Table 4 Hardness and wear rate of fly ash-based geopolymers with $5 \%$ wt addition of silica fume addition.

\begin{tabular}{lll}
\hline Specimen & Hardness $(\mathrm{BHN})$ & Wear rate $\left(\mathrm{mm}^{3} / \mathrm{min}\right)$ \\
\hline \multicolumn{2}{l}{ Room temperature curing } \\
\hline 1 & 67.7355 & 0.6112 \\
2 & 66.0675 & 0.5911 \\
3 & 59.9044 & 0.7826 \\
Average value & 64.5691 & 0.6616 \\
\hline $80^{\circ} \mathrm{C}$ curing & \\
\hline 1 & 46.2259 & 4.1334 \\
2 & 39.7940 & 0.8893 \\
3 & 41.7771 & 0.3728 \\
\hline Average value & 42.5990 & 1.7985 \\
\hline
\end{tabular}


possibly due to the formation of more cracks at higher curing temperatures. Opposite to hardness, geopolymers cured at $80^{\circ} \mathrm{C}$ were more wear resistant than the one cured at room temperature, however so, the wear rate in general was relatively low.

\section{Conclusions}

The major problem in geopolymer application on ordinary concrete was cracking due to shrinkage. Cracks develop immediately after curing when the hardened geopolymer is exposed to air due to water evaporation. Geopolymer mix contains significant amount of water required as medium for reaction while curing of geopolymer is a condensation reaction which produces water, on the contrary to the hardening of ordinary Portland cement which consumes water. The application of geopolymer paste on Portland cement substrate would cause absorption of water required for the curing process of geopolymer, for the prolonged hydration process of the Portland cement. This is the reason of the severe cracking of the geopolymer layer. For this reason, geopolymer for flooring and covering should not be applied on Portland cement concrete substrate. Compressive strength of the geopolymer paste, regardless of it being applied on a substrate, is higher when curing temperature is higher, however cracking become more pronounced when curing at higher temperatures. The average compressive strength of the paste were 12, 53 and $67 \mathrm{MPa}$ for curing at ambient temperature, 60 and $80^{\circ} \mathrm{C}$ respectively with a curing time of 24 hours. Like the compressive strength, hardness decreased with increasing curing temperatures, from 65 to $43 \mathrm{BHN}$ for geopolymer cured at 60 and $80^{\circ} \mathrm{C}$ respectively. The decrease in hardness was reflected in the increase of wear rate from 0.66 to $1.80 \mathrm{~mm}^{3} / \mathrm{min}$. The addition $5 \%$ wt of silica fume into the geopolymer paste reduced craking fairly, however the compressive strength decrease with the addition of silica fume from $53 \mathrm{MPa}$ to $37 \mathrm{MPa}$ for the paste cured at $60^{\circ} \mathrm{C}$. Silica flour should be added to reduce shrinkage instead of silica fume. The relatively low hardness, which is the the range of mineral gypsum, and wear resistance of geopolymer surface hinders its application for flooring, however the near net shaping of the material makes it suitable for decoration purpose.

\section{Acknowledgments}

This research has been funded by the Ministry of Education under the scheme Hibah Bersaing 2011-2012.

\section{References}

[1] S. Astutiningsih and Y. Liu, Geopolymerisation of Australian slag with effective dissolution by the Alkali, in: Proc. of the World Congress Geopolymer 2005, Geopolymer Institute, Saint Quentin, France, June 29-July 1, 2005, pp. 69-73

[2] A. Palomo, M. Y. Blanco-Varela, M. L. Ranizo, F. Puertas, T. Vazques and M. W. Grutzeck, Chemical stability of cementitious materials based on metakaolin, Cement and Concrete Research 29 (1999) 997-1004.

[3] J. Davidovits, Technical Talk: Geopolymer Applications, Curtin University, Western Australia, Oct. 25, 2002.

[4] H. Rahier, B. Van Mele, J. Wastiels and X. Wu, Low-temperature synthesized aluminosilicate glasses: Part I Low-temperature reaction stoichiometry and structure of a model compound, Journal of Materials Science 22 (1996) 71-79.

[5] H. Rahier, B. Van Mele and J. Wastiels, Low-temperature synthesized aluminosilicate glasses: Part II Rheological transformation during low-temperature cure and high-temperature properties of a model compound, Journal of Materials Science 31 (1996) 80-85.

[6] H. Rahier, W. Simons and B. Van Mele, Low-temperature synthesized aluminosilicate glasses: Part III Influence of the composition of the silicate solution on production, structure and properties, Journal of Materials Science 32 (1997) 2237-2247.

[7] W. K. W. Lee and J. S. J. Van deventer, The effect of inorganic salt contamination on the strength and durability of geopolymer, Colloids and Surfaces A: Physicochemical and Eng. Aspects 211 (2002) 115-126.

[8] J. G. S Van Jaarsveld and J. S. J. Van Deventer, The effect of metal contaminants on the formation and properties of waste-based geopolymer, Cement and Concrete Research 29 (1999) 1189-1200.

[9] P. Chindraprasirt, T. Chareerat and V. Sirivivatnanon, Workability and strength of coarse high calcium fly ash 
geopolymer, Cement and Concrete Composites 29 (2007) 224-229.

[10] C. K. Yip, G. C. Lukey, J. L. Provis and J. S. J. van deventer, Effect of calcium silicate sources on geopolymerisation, Cement and Concrete Research 38 (2008) 554-564.
[11] Davidovits, Mineral Polymers and methods of making them, US Patent, 4349386 (1982).

[12] G. E. Dieter, Mechanical metallurgy, Mc-Graw Hill, 1987, pp. 326-327.

[13] S. Astutiningsih, Alkali activation and curing of aluminosilicate based-geopolymers, Ph.D. Thesis, The University of Western Australia, 2005, p. 98. 